\title{
The management and outcome in children admitted to hospital
}

\author{
S. D. M. COURT \\ Emeritus Professor of Child Health, University of Newcastle-Upon-Tyne
}

\section{Summary}

2418 children aged 0-14 years were admitted to hospital with respiratory infections; 2396 recovered and $22(0.9 \%)$ died.

Previous respiratory illness had been experienced by $5.6 \% ; 2.6 \%$ had congenital heart disease and $0.6 \%$ cystic fibrosis.

Antibiotics were given in every category of illness; the frequency varied from $68 \%$ in colds to $97 \%$ in pneumonia. Oxygen was given to $14 \%$ of children with croup, $29 \%$ with bronchiolitis and $13 \%$ with pneumonia. No child with upper respiratory infection or croup died. The case mortality in the 1295 children with lower respiratory infections was $1.7 \%: 0.6 \%$ in bronchitis, $0.7 \%$ in bronchiolitis, and $3 \cdot 1 \%$ in pneumonia.

Pathogenic infective agents were isolated in half the deaths; and in $36 \%$ predisposing malformations or disease were present.

With a limited study of management and outcome deductions must be made with caution. It suggests, however, that therapy based on understanding of the infective agents and the respiratory dysfunction to which they give rise is not as yet generally applied.

\section{Management}

This survey was primarily designed to study the relationship between clinical categories and viruses in children admitted to hospital with respiratory infection. No comprehensive assessment of management was made therefore, but treatment with chemotherapy, antibiotics and oxygen were recorded. We hoped that this would throw some light on the relationship of these to our clinical categories and the infective agents associated with them.

\section{Antibiotics}

The use of antibiotics is shown in Table 1. They were given in every category of illness; the frequency varying from $68 \%$ of children with common colds to $97 \%$ of those with pneumonia.

The main antibiotics used were: benzyl-penicillin in $62 \%$ of all illnesses, tetracycline in $16 \%$, and a combination of penicillin and tetracycline in $10 \%$.
TABLE 1. The use of antibiotics and chemotherapy in each clinical category

\begin{tabular}{lcc}
\hline & $\begin{array}{c}\text { No. of } \\
\text { children }\end{array}$ & $\begin{array}{c}\text { Usage } \\
(\%)\end{array}$ \\
\hline Common cold & 232 & $68 \cdot 5$ \\
Pharyngitis & 244 & $77 \cdot 0$ \\
Tonsillitis & 257 & $89 \cdot 5$ \\
Primary otitis media & 142 & $95 \cdot 1$ \\
Croup & 230 & $85 \cdot 7$ \\
Bronchitis & 453 & $92 \cdot 5$ \\
Bronchiolitis & 303 & 86.1 \\
Pneumonia & 543 & 96.9 \\
Influenza & 14 & 28.5 \\
All diagnoses & 2418 & 87.6 \\
\hline
\end{tabular}

TABLE 2. The use of oxygen in each clinical category

\begin{tabular}{lcc}
\hline & $\begin{array}{c}\text { No. of } \\
\text { children }\end{array}$ & $\begin{array}{c}\text { Usage } \\
(\%)\end{array}$ \\
\hline Common cold & 232 & $1 \cdot 7$ \\
Pharyngitis & 244 & 0 \\
Tonsillitis & 257 & $0 \cdot 4$ \\
Primary otitis media & 142 & 0 \\
Croup & 230 & 14.3 \\
Bronchitis & 453 & 6.6 \\
Bronchiolitis & 299 & $28 \cdot 7$ \\
Pneumonia & 543 & 13.4 \\
\hline
\end{tabular}

The use of oxygen in each clinical category is shown in Table 2. The limited use of oxygen in bronchiolitis and pneumonia was unexpected. As cyanosis was recorded in $40 \%$ of infants under 6 months of age, in $19 \%$ of those between 6 months and 1 year, and in $23 \%$ of children from 1 to 4 years, we suspect that the frequency of oxygen administration was under-recorded.

\section{Duration of stay in hospital}

The length of stay in hospital is shown in Table 3. Nearly half the children were there for less than 5 days, and by the fifteenth day more than $90 \%$ had been discharged. The distribution was different for upper and lower respiratory illnesses; only one-third of those with upper respiratory illnesses or croup were in hospital for more than 5 days, compared with $60 \%$ of those with bronchitis and $75 \%$ of those 
TABLE 3. Duration of stay in hospital for each clinical category

( $\%$ in hospital for different periods)

\begin{tabular}{|c|c|c|c|c|c|c|c|c|c|c|c|}
\hline \multirow{2}{*}{$\begin{array}{l}\text { Days in } \\
\text { hospital }\end{array}$} & \multirow[t]{2}{*}{ 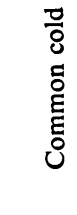 } & \multirow[t]{2}{*}{ 营 } & \multirow[t]{2}{*}{ 兰 } & \multirow[t]{2}{*}{ 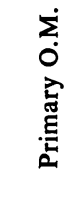 } & \multirow{2}{*}{ 을 } & \multirow[t]{2}{*}{ 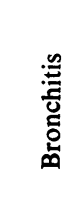 } & \multirow[t]{2}{*}{ 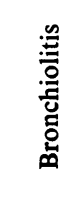 } & \multirow[t]{2}{*}{ 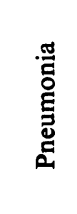 } & \multirow[t]{2}{*}{ 胥 } & \multicolumn{2}{|c|}{ Total } \\
\hline & & & & & & & & & & No. & $\%$ \\
\hline 3 & 31 & 28 & 30 & 21 & 25 & 9 & 2 & 4 & 36 & 379 & 16 \\
\hline $3-5$ & 34 & 43 & 42 & 42 & 44 & 31 & 22 & 20 & 29 & 773 & 32 \\
\hline $6-10$ & 19 & 22 & 20 & 23 & 23 & 39 & 52 & 37 & 36 & 775 & 32 \\
\hline $11-15$ & 9 & 5 & 6 & 6 & 5 & 13 & 16 & 20 & - & 286 & 12 \\
\hline $16-20$ & 3 & 0.4 & 1 & 1 & 2 & 4 & 4 & 9 & - & 97 & 4 \\
\hline $21+$ & 3 & 0.4 & 1 & 4 & 1 & 4 & 4 & 10 & - & 105 & 4 \\
\hline Not stated & - & 0.4 & - & 1 & - & - & - & - & - & 3 & - \\
\hline $\begin{array}{l}\text { Total } \\
\text { admissions }\end{array}$ & $\begin{array}{c}232 \\
(100)\end{array}$ & $\begin{array}{c}244 \\
(100)\end{array}$ & $\begin{array}{c}257 \\
(100)\end{array}$ & $\begin{array}{c}142 \\
(100)\end{array}$ & $\begin{array}{c}230 \\
(100)\end{array}$ & $\begin{array}{c}453 \\
(100)\end{array}$ & $\begin{array}{c}303 \\
(100)\end{array}$ & $\begin{array}{c}543 \\
(100)\end{array}$ & $\begin{array}{c}14 \\
(100)\end{array}$ & 2418 & (100) \\
\hline
\end{tabular}

with bronchiolitis or pneumonia. Young infants tended to be kept in for longer than older children, irrespective of the diagnosis. Although duration of admission generally reflects the severity of an illness, other considerations, such as the child's social background and variations in ward staffing and medical management affect the length of an individual child's stay in hospital, and made comparisons between different centres unreal.

\section{Previous health}

The pattern of illness, management and outcome may be affected by predisposing disease or by previous experience of respiratory infection. We recorded this and $386(16 \%)$ of the total group were involved. The nature of their previous or predisposing illnesses is shown in Table 4. This Table reflects two distinct processes; recurrence of respiratory illness is to be expected in early childhood and the history of previous infection in more than $5 \%$ of children supports this; in addition $2.8 \%$ had congenital heart disease and $0.6 \%$ cystic fibrosis, conditions which may lead to more severe, more prolonged, or continuing infection.

\section{Outcome}

2418 children were studied, 2396 survived, twenty two died. Of the surviving children, $83 \%$ were well on discharge and $17 \%$ had continuing respiratory symptoms. The duration of this post-hospital illhealth and any persisting respiratory damage were not measured.

\section{Deaths}

Twenty-two of the 2418 children $(0.9 \%)$ died. The details which were recorded are shown in Table 5.

TABLE 4. Children with predisposing disease or previous respiratory illness in each clinical category

\begin{tabular}{|c|c|c|c|c|c|c|c|c|c|c|}
\hline Present illness & $\mathrm{CC}$ & Ph. & Ts. & POM. & Croup & Brs. & Bls. & Pna. & \multicolumn{2}{|c|}{ All children } \\
\hline No. of children & 232 & 244 & 257 & 142 & 230 & 453 & 299 & 543 & \multicolumn{2}{|c|}{2404} \\
\hline $\begin{array}{l}\text { Past or predisposing } \\
\text { illnesses }\end{array}$ & & & & & & & & & No. & $\%$ \\
\hline Croup & - & - & - & - & 10 & - & - & 2 & 12 & 0.5 \\
\hline Bronchitis & 3 & 3 & 3 & 2 & 4 & 37 & 10 & 28 & 90 & $3 \cdot 7$ \\
\hline Bronchiolitis and pneumonia & 2 & 2 & 0 & 0 & 2 & 2 & 3 & 10 & 21 & 0.9 \\
\hline Other L.R.T. illnesses & 0 & 1 & 1 & $\mathbf{0}$ & 1 & 2 & 1 & 5 & 11 & 0.5 \\
\hline Cystic fibrosis & 4 & 3 & 0 & 0 & 0 & 1 & 0 & 6 & 14 & 0.6 \\
\hline Congenital heart disease & 5 & 5 & 5 & 1 & 2 & 16 & 5 & 30 & 69 & $2 \cdot 8$ \\
\hline $\begin{array}{l}\text { Central nervous system disease } \\
\text { and mental deficiency } \\
\text { Miscellaneous }\end{array}$ & $\begin{array}{r}2 \\
10\end{array}$ & $\begin{array}{r}1 \\
19\end{array}$ & $\begin{array}{r}3 \\
29\end{array}$ & 1 & $\begin{array}{l}2 \\
4\end{array}$ & $\begin{array}{r}1 \\
32\end{array}$ & $\begin{array}{l}2 \\
8\end{array}$ & $\begin{array}{l}10 \\
35\end{array}$ & $\begin{array}{r}22 \\
148\end{array}$ & $\begin{array}{l}0.9 \\
6 \cdot 2\end{array}$ \\
\hline $\begin{array}{l}\text { No. } \\
\%\end{array}$ & $\begin{array}{c}26 \\
11 \cdot 2\end{array}$ & $\begin{array}{c}34 \\
13 \cdot 9\end{array}$ & $\begin{array}{c}41 \\
16 \cdot 0\end{array}$ & $\begin{array}{c}15 \\
10 \cdot 6\end{array}$ & $\begin{array}{c}25 \\
10 \cdot 9\end{array}$ & $\begin{array}{c}91 \\
20 \cdot 1\end{array}$ & $\begin{array}{l}29 \\
9 \cdot 2\end{array}$ & $\begin{array}{l}126 \\
23 \cdot 2\end{array}$ & $\begin{array}{l}387 \\
16 \cdot 1\end{array}$ & \\
\hline
\end{tabular}




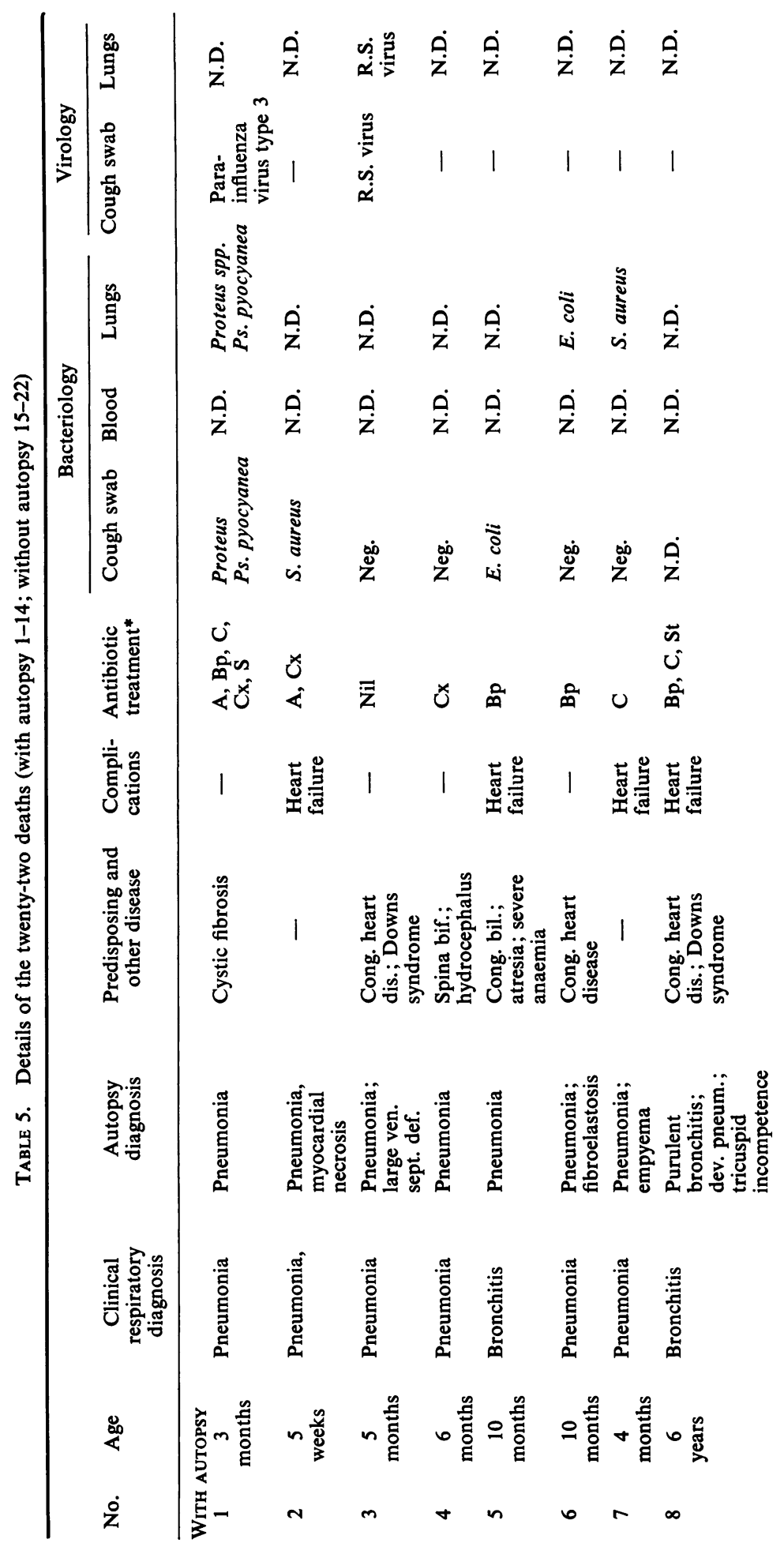




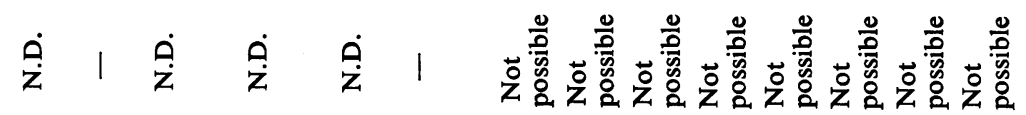

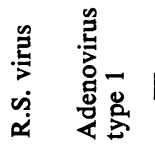

量

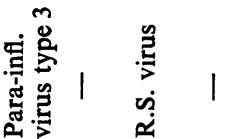

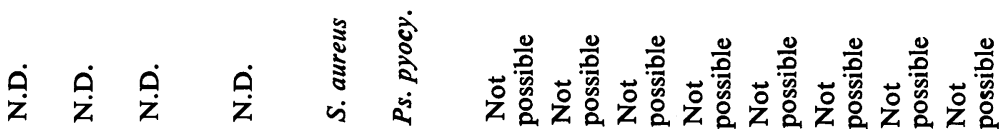

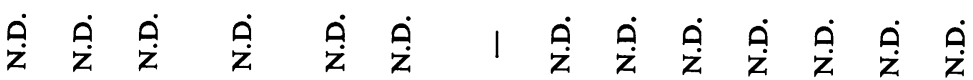

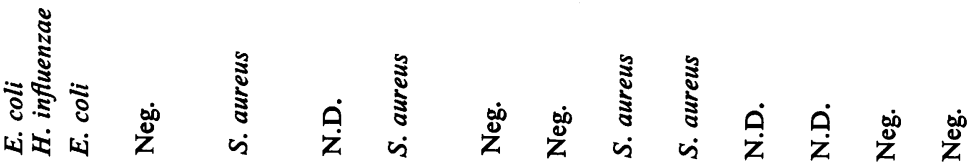

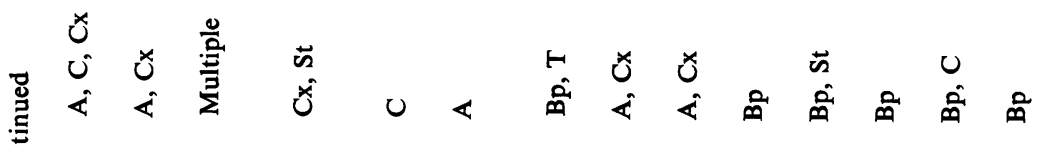

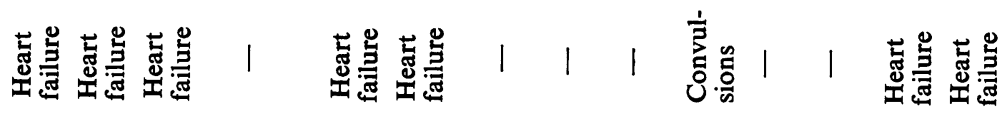

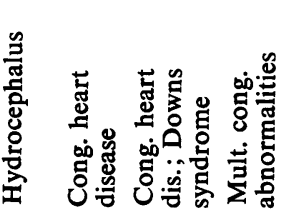

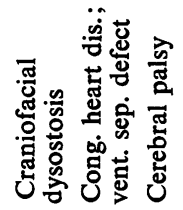

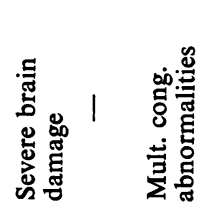

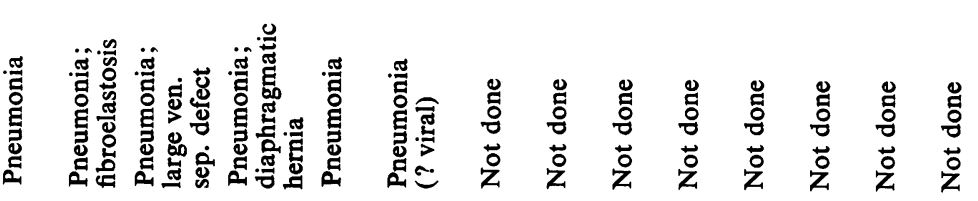

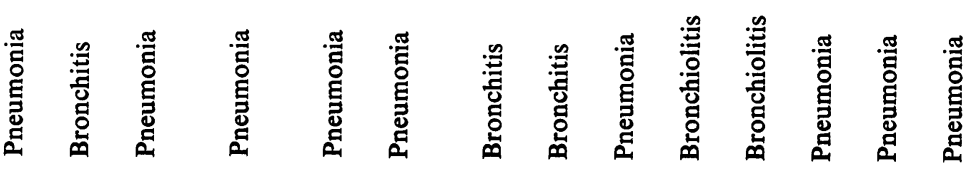

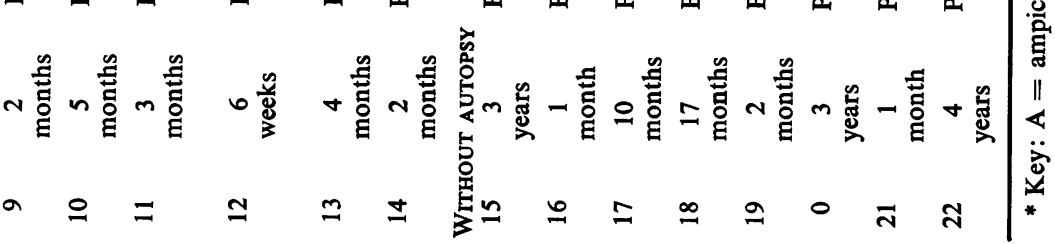


There were no deaths in children with upper respiratory infection or with croup. Among the 1295 with lower respiratory infection the case mortality was $1.7 \% ; 0.6 \%$ in bronchitis, $0.7 \%$ in bronchiolitis and $3.1 \%$ in pneumonia.

The facts behind these figures are incomplete for two main reasons; necropsy was not permitted in eight children and no standard procedures for postmortem bacterial or virus examination of the lungs and for histological examination were laid down in the survey protocol. However, useful information about the context and causes of death was obtained.

There were fifteen boys and seven girls, conforming to the male preponderance present in all categories of respiratory illness. The case mortality rate in children under 1 year of age was $1.6 \%$ and in children under 6 months it was $2 \%$. The following observations on the data presented in Table 5 can be fairly made.

\section{Infection}

The distribution of bacterial and virus infections and their broad relation to predisposing disease was as follows: primary bacterial, two; presumed primary bacterial, one; primary viral, four; bacterial with predisposing disease, one; viral with predisposing disease, two; bacterial and viral with predisposing disease, one; no infective agent found, eleven.

\section{Primary}

Pathogenic infective agents were isolated in half the deaths. They were considered to be causally related to the disease, though the evidence was not equally strong in all cases.

Two cases of primary bacterial pneumonia $(7$ and 13) were due to Staphylococcus aureus. They occurred in previously healthy children, both aged 4 months; the organism was obtained at autopsy from multiple lung abscesses in one infant and from pneumonia with associated empyema in the second. A third child, aged 5 weeks, and previously healthy also probably died of $S$. aureus pneumonia; the radiological appearances were consistent with this diagnosis and the organism was isolated from a cough swab. She was treated with cloxacillin and ampicillin and was making a satisfactory recovery when, 8 days after admission, on the tenth day of her illness she suddenly developed left heart failure and died. At necropsy a resolving bacterial pneumonia was present together with a large area of myocardial necrosis in the left ventricle without associated vascular occlusion. Neither blood culture during life nor bacteriology of the lung at necropsy was carried out.

Of the four primary virus infections only one (9) came to necropsy. This was a child aged 2 months;
R.S. virus was isolated from a cough swab and the histological picture was consistent with virus pneumonia. The next child (21), aged 1 month, had clinical pneumonia, and R.S. virus was isolated from the cough swab. Admitted within $24 \mathrm{hr}$ of the onset of symptoms the illness was severe with recurrent periods of apnoea in which assisted respiration became necessary. Although given oxygen, chloramphenicol and benzyl penicillin he died suddenly on the seventh day of his illness from cardiac arrest. The third death was in a child aged 3 years with a clinical diagnosis of severe bronchitis without radiological evidence of pneumonia; R.S. virus, was isolated from the cough swab. In the fourth child, aged 2 months, the clinical diagnosis was pneumonia, but a review of the symptoms suggested that a diagnosis of bronchiolitis would have conformed more closely to the agreed clinical classification. Parainfluenza virus type 3 , was isolated from the cough swab. The illness lasted only $48 \mathrm{hr}$ and he died $24 \mathrm{hr}$ after admission. Pathogenic bacteria were not isolated from the cough swabs in these children.

Three of the four children were considered normal and well before their fatal illness; the fourth had cranio-facial dysostosis but this was thought to have had no more than a marginal effect on the fatal respiratory illness.

R.S. virus and parainfluenza virus are rarely obtained from the respiratory secretions in the absence of clinical respiratory disease.

\section{Infection with predisposing disease}

There were four children in this group. The first, (6), aged 10 months, died within $48 \mathrm{hr}$ of the onset of illness and $24 \mathrm{hr}$ after admission to hospital; no pathogenic bacterium or virus was isolated from the cough swab. Lung puncture and necropsy bacteriology less than $24 \mathrm{hr}$ after death showed a profuse growth of $E$. coli. Histology showed a bilateral haemorrhagic bronchopneumonia. The child's development was delayed, probably as a result of anoxia at birth, and she had severe heart disease due to fibroelastosis. Although blood culture was not carried out during life it was though this could have been an $E$. coli septicaemia with widespread pneumonia.

In the next two children death was associated with virus infection. The first, (3), aged 5 months, had Down's Syndrome with a large ventricular septal defect; at necropsy the greater parts of both lungs were pneumonic, and R.S. virus was isolated from the lungs. It had previously been isolated from the cough swab and blood culture was sterile. The picture in the second child, (10), a girl aged 5 months, was less clear. A diagnosis of pneumonia had been made, but without radiography. Four days after the onset 
of her illness and within $24 \mathrm{hr}$ of admission to hospital she died and at necropsy there was widespread bilateral bronchopneumonia together with fibroelastosis, and heart failure. Adenovirus type 1 was isolated from a cough swab. Pathogenic bacteria were not found in the upper respiratory tract. Blood culture was not carried out, and the lungs were not cultured. Adenovirus type 1 was the probable cause of the pneumonia, which, together with heart failure, led to her death.

The fourth child, (1), was aged 3 months and Pseudomonas pyocyanea, B Proteus and parainfluenza virus type 3 were obtained from the cough swab. The predisposing condition was cystic fibrosis and a widespread suppurative bronchitis was present with areas of consolidation. It seems reasonable to assume that parainfluenza virus infection was the terminal event in the child's progressive bacterial pulmonary suppuration.

\section{Predisposing malformations or diseases}

Of the twenty-two children who died, eight (36\%) had malformations or diseases known to be associated with recurrent or continuing respiratory infection; the comparable figure for the whole group was $3.4 \%$. Six children had severe congenital heart disease (three of these had large septal defects, one a tricuspid anomaly, and two had fibroelastosis; in three this was part of Down's Syndrome). One child had cystic fibrosis. One had multiple congenital abnormalities which included, in addition to a left diaphragmatic hernia with lung compression and defective lung development, micrognathos, small posterior nares and a poorly developed larynx.

\section{Associated malformations or diseases}

Other conditions which may have contributed were present in seven children: two had meningomyelocele and hydrocephalus, two severe cerebral palsy, one congenital biliary atresia, one craniofacial dysotosis, and one multiple abnormalities. Their relation to death was not easy to assess but in one child with severe brain damage it was decided that treatment would be unhelpful.

\section{Acute processes developing during the illness and contributing to death}

These occurred in sixteen of the twenty-two children. Heart failure was recorded in eleven, and considered to be the primary cause of death in six. Although diagnosis may be difficult, heart failure is associated with acute respiratory infection and its importance in severe and fatal cases was confirmed in this study. Hyperpyrexia, with temperatures of $106^{\circ} \mathrm{F}, 107^{\circ} \mathrm{F}$ and $108^{\circ} \mathrm{F}$, was recorded in three children, and its threat to survival is well known.

Convulsions occurred in five children; this frequency $(23 \%)$ is higher than in the lower respiratory infections as a whole but in only one child were they thought to have been a major factor in the death. One child was severely anaemic.

\section{Treatment}

Except for two children, one of whom died immediately after admission and the other of whom had severe incurable brain disease suggesting that intensive treatment would be unjustified, all were given oxygen and antibiotics. The antibiotics used in these twenty children were: benzyl penicillin in five, cloxacillin and ampicillin in five, chloramphenicol alone or with other antibiotics in five, benzylpenicillin with streptomycin or tetracycline in three, cloxacillin in one, and ampicillin in one.

\section{Conclusions}

Analysis of these twenty-two deaths, while not adding new knowledge, has underlined some important facts. Acute respiratory infection is still a special hazard in the first year of life. There were seven primary pneumonias: four were viral, three R.S. virus and one parainfluenza virus; three bacterial all due to Staph. pyogenes.

Serious malformations, or diseases known to predispose to respiratory infection, were present in eight children, more than one third of the fatal group. In three of these children the terminal illness was a viral and in one a bacterial infection. Recognition of this association has important implications for management during life and certification at death. In the events leading to death, infection, malformation and underlying disease may together produce dangerous systemic and cellular disturbance especially heart failure and hyperpyrexia.

Yet the picture is still incomplete. The degree of dehydration was not recorded, and for only two of the twenty-two children was information about the child's metabolic state, available. These are important gaps since it is increasingly recognized that hypoxia, dehydration and respiratory and metabolic acidosis are dangerous accompaniments of severe respiratory infection. A larger more detailed study of death in children with respiratory infection is urgently needed if the figure of 3000 deaths attributed to acute respiratory infection, recorded annually in England and Wales is to become more meaningful than it is at present. 